\title{
The Odyssey of suturing cardiac wounds: lessons from the past.
}

\author{
Erwan Flecher ${ }^{1}$, Alain Leguerrier ${ }^{1}$, and Nicolas Nesseler ${ }^{1}$ \\ ${ }^{1} \mathrm{CHU}$ Pontchaillou
}

May 11, 2020

\begin{abstract}
Cardiac wounds have been described for centuries and still remain often fatal. For a long period of time suture of a myocardial laceration was thought to be absolutely impossible if not sacrilege. It is only at the end of the 19th century that pioneers decided to defy such dogma in desperate cases. Nowadays it seems obvious that a cardiac stab wound require emergent surgery whenever possible. The story of cardiac wounds highlights nicely the change of mind that is required to accept progress and new procedures in medicine.
\end{abstract}

\section{Introduction}

Cardiac wounds have been described from many centuries as the earliest known appeared in Homer's iliad. To date stab wounds to the heart remain a life-threatening injury. Their management is still highly challenging and requires immediate care and transfer to a surgical atmosphere. Even nowadays despite medicalized helicopters, ambulances and presence of well distributed hospitals on our territory, a cardiac penetrating wound is often fatal. Moreover it is only 123 years ago that the first successful repair of a cardiac wound was reported, passing through a long history of mysticism and medical criticism. Herein we report a brief overview of the care of cardiac penetrating wounds, illustrating also the birth of cardiac surgery and how dogma in medicine should be criticized.

\section{From Mysticism to criticism}

Heart wounds have been described for centuries. Iliad and Odyssey manuscript contains references to weapons implanted in the chest, mainly by spearing, and thirty-four cases of thorax-torso trauma are reported in the epics [1]. This legendary story even described the cardiac impulse transmitted through a spear that hurt in the chest Alkathoos. Some historians and researchers suggested that Homer himself might have been a military surgeon to provide so precise descriptions of the treatment of battle wounds [2]. According to Aristotle ( $3^{\text {rd }}$ century AD) the heart was a vital organ that may not withstand major affection. Moreover Galen $\left(2^{\text {nd }}\right.$ century $\mathrm{AD}$ ) who had to manage severe injuries in warriors and gladiators reported that cardiac penetrating wounds were fatal in all cases. One should keep in mind that Galen kept a scornful look about surgery and described wrongly the human heart anatomy and function. As he embarked on monotheism and Catholicism, his point of view was carved in stone for centuries. Ambroise Pare $\left(16^{\text {th }}\right.$ century), who started his career as a barber-surgeon and is considered for many as the father of surgery, described later the prognosis of cardiac wounds and reported the autopsy of a man stabbed to the heart at Turin, Italy(3). At that time, and according to Fabricius, it appeared obvious that "if the heart is wounded the affair is desperate and it is therefore unnecessary to attempt any treatment" [3]. If Francesco Romero is considered by some authors to be the first surgeon having drained a pericardial effusion in 1801, the Baron Dominique Jean Larrey also reported in 1810 his first pericardiotomy on a soldier who tried to commit suicide by stabbing himself in the chest $[4,5]$. Although this Surgeon-in-Chief of the Grand Army did not suture any heart wound, he drained the pericardium space and described a surgical approach to do so, through the base of the xiphoid (still known as the Larrey point). 
Despite the beginning of few animal experiments by Block in 1882, contemporary opinions on heart surgery at that time were set up as dogma and in 1883 the well-known Austrian surgeon Theodor Billroth even declared: "the surgeon who should attempt to suture a wound of the heart would lose the respect of his colleagues" [5]. Moreover in 1896 the British surgeon Stephen Paget established a fatalistic statement: "Surgery of the heart has probably reached limits set by nature to all surgery. No new method; and no new discovery, can overcome the natural difficulties that attend a wound of the heart" [6].

\section{First suture of a cardiac stab wound (See Figure 1 and Video)}

With this overall pessimism about heart surgery in mind, the first reported suture of a myocardial laceration was performed by the Norwegian surgeon Axel Cappelen in 1895[7]. A 24-year-old male had a stab wound to the left chest. He performed a left thoracotomy of the fourth intercostal space, found a 2-cm laceration of the left ventricle and sutured it using katgut material. The operation was performed under chlorophorm anesthesia but unfortunately the patient died on postoperative sepsis 3 days later. As this first suture on a human beating heart ended in death, this historical operation has been overshadowed by the successful suture of a right ventricle injury by the German surgeon Ludwig Rehn few months later. Indeed, in September 1896 in Frankfurt, a 22-year-old gardener was stabbed in the chest. Rehn, who was a self-taught surgeon without any prior experience with heart surgery, realized a left thoracotomy and observed a wound measuring approximately $1,5 \mathrm{~cm}$ in the middle of the right ventricle. He sutured the heart wound, applying ordinary surgical principles. The patient recovered and Rehn reported 6 months later this procedure at the German Society of Surgery.

One year later (1897) was performed in Rome the first suture of the left ventricle by the surgeon Antonio Parrozzani and in 1907 Rehn reported 124 cases of surgical treatment of heart wounds and a $60 \%$ mortality rates [3], which was still much less than the conservative and nonoperative treatment...

\section{The role of sternotomy and world war two in the treatment of cardiac wound}

All these pioneers entered the chest through an intercostal approach, with or without rib resection. Herbert Nelson Milton was a british medical officer at the Kasr El Aini Hospital in Cairo and had to operate on many patients requiring emergent thoracic surgery. In 1897 he reported a direct approach to the mediastinum as an "anterior median thoracic incision" that is in fact a median sternotomy [8]. He declared: "So easy is this incision of execution and so considerable is the power of exploration thereby obtained that one is almost induced to hope that future experience may justify the application to it of the term normal thoracic incision". This approach is nowadays the gold standard for cardiac surgeons not only for cardiopulmonary bypass surgery but also to safely and quickly manage a cardiac stab wound.

Medical and surgical knowledge particularly have always benefited from wars and World War II was an opportunity to observed shell fragments and other missiles in human hearts. Blalock and Ravith published in 1943 the use of pericardiocentesis to deal with cardiac wounds in soldiers but it is truly Dwight Harken who revolutionized this dreadful management [9]. Harken was called to duty as a consultant thoracic surgeon and he reported in 1946 an impressive experience that clearly inspired surgeons regarding the development of cardiac surgery [10]. Indeed, over a 10 months period, Harken removed 78 missiles that were within or in proximity to the great vessels; he extracted 56 foreign bodies from the heart, 13 of them from the cardiac cavities! He operated on 134 patients with chest and cardiac wounds without a single death. One should keep in mind that cardiopulmonary bypass did not exist at that time and Harken's work helped to change the field of cardiac surgery.

Since World War II many improvements in the management of penetrating cardiac injuries have been reported which include the use of echocardiography, emergency department thoracotomy, pericardial drainage, fluid management and use of vasoactive drugs for restoration of blood pressure. Despite these evident improvements, the outcome of a penetrating cardiac injury remains poor even in western countries urban trauma centers...

\section{Conclusion}


This brief story of cardiac wound illustrates how it is important to keep an opened mind in medicine. Next generations of cardiologists, anesthsiologists and cardiac surgeons will have new challenges to overcome that may appear impossible to cure at this time. However, what seems impossible today may become standard routine of care in the future. Fear and criticism about new procedures are unavoidable but should represent for pioneers a boundary to break down.

\section{FIGURE LEGENDS}

Figure 1: Cardiac stab wounds

Video 1: Knife in the cardiac area just before emergent surgery

\section{REFERENCES}

1. Nomikos N. Injuries in the Greek epics of Homer. Chinese journal of traumatology = Zhonghua chuang shang za zhi. 2018;21(2):109-12.

2. B G. Was Homer a surgeon? Chirurgie. 1990;116(2):136-43.

3. Asensio JA, Petrone P, Pereira B, Pena D, Prichayudh S, Tsunoyama T, et al. Penetrating cardiac injuries: a historic perspective and fascinating trip through time. Journal of the American College of Surgeons. 2009;208(3):462-72.

4. Remba SJ, Varon J, Rivera A, Sternbach GL. Dominique-Jean Larrey: the effects of therapeutic hypothermia and the first ambulance. Resuscitation. 2010;81(3):268-71.

5. Alexi-Meskishvili V, Bottcher W. Suturing of penetrating wounds to the heart in the nineteenth century: the beginnings of heart surgery. The Annals of thoracic surgery. 2011;92(5):1926-31.

6. Harken DE, Curtis LE. Heart surgery-legend and a long look. The American journal of cardiology. 1967;19(3):393-400.

7. Soreide K, Soreide JA. Axel H. Cappelen, MD (1858-1919): first suture of a myocardial laceration from a cardiac stab wound. The Journal of trauma. 2006;60(3):653-4.

8. van Wingerden JJ. Sternotomy and intrathoracic omentum: two procedures, two innovators, and the river that runs through it - a brief history. The Annals of thoracic surgery. 2015;99(2):738-43.

9. Blalock A RM. Consideration of nonoperative treatment of cardiac tamponade resulting from wounds of the heart. Surgery. 1943;14:157-62.

10. Symbas PN, Justicz AG. Quantum leap forward in the management of cardiac trauma: the pioneering work of Dwight E. Harken. The Annals of thoracic surgery. 1993;55(3):789-91.

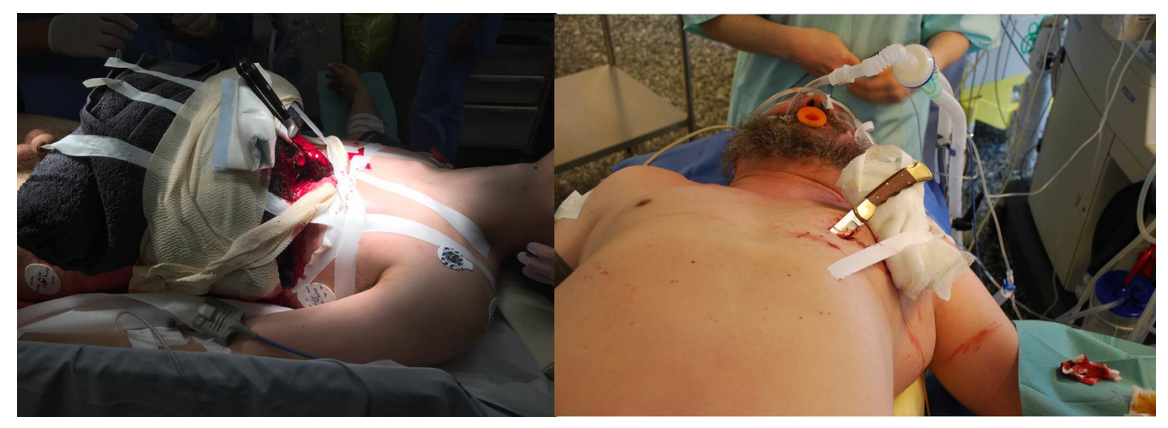

